Portland State University

PDXScholar

1971

\title{
A series of paintings which investigate and present volume experience as an aspect of spatial tension with hue variations as a prime agent
}

Carl B. Clapp

Portland State University

Follow this and additional works at: https://pdxscholar.library.pdx.edu/open_access_etds

Part of the Art and Design Commons, and the Art Education Commons Let us know how access to this document benefits you.

Recommended Citation

Clapp, Carl B., "A series of paintings which investigate and present volume experience as an aspect of spatial tension with hue variations as a prime agent" (1971). Dissertations and Theses. Paper 1525. https://doi.org/10.15760/etd.1525

This Thesis is brought to you for free and open access. It has been accepted for inclusion in Dissertations and Theses by an authorized administrator of PDXScholar. Please contact us if we can make this document more accessible: pdxscholar@pdx.edu. 
AN ABSTRACT OF THE THESIS OF CARL B. CLAPP for the Master of Science in Teaching presented May $17,1971$.

Title: A sexies of paintings which investigate and present volume experience as an aspect of spatial tension with hue variations as a prine agent.

APPROVED BY MEMBERS OF THE THESIS COMMTTEE:
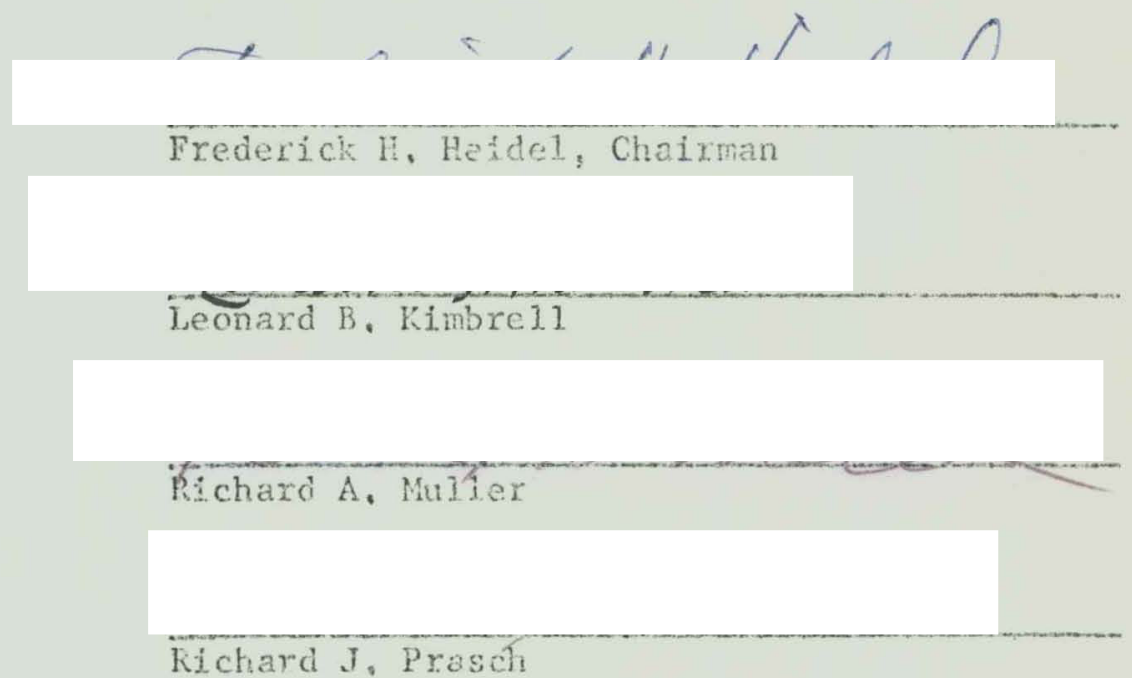

This thesis work is concerned with volume as presented in a painting. The investigation begins with a painting of dram geometric shapes. Each successive painting problem explores additional facets or variations from this basic problem.

There is a total of six painting probiens, The general intent: of these problens is to investigate the following in regard to volume experience:

1. color contrast in hue, value, intensity, proportion and complement

2. pattern variations

3. the color phenomenon of simitaneous contrast. 
The medium is acrylic polymer emulsion applied with brush on stretched canvas. 


\section{A SERIES OF PATNTINGS}

WHICH INVESTIGATE AND PRESENT VOLUME EXPERIENCE

AS AN ASPECT OF SPATIAL TENSION

WITH HUE VARTATIONS AS A PRTME AGENT.

by

CARL B, CLAPP

A thesis submitted in partial fulfillment

of the requirements for the degree of

MASTER OF SCIENCF:

in

TEACHING

:ortland State University

1971 
TO THE OFFICE OF GRADUATE STUDIES:

The members of the Comnittee approve the thesis of Carl B. Clapp presented May 17, 1971.

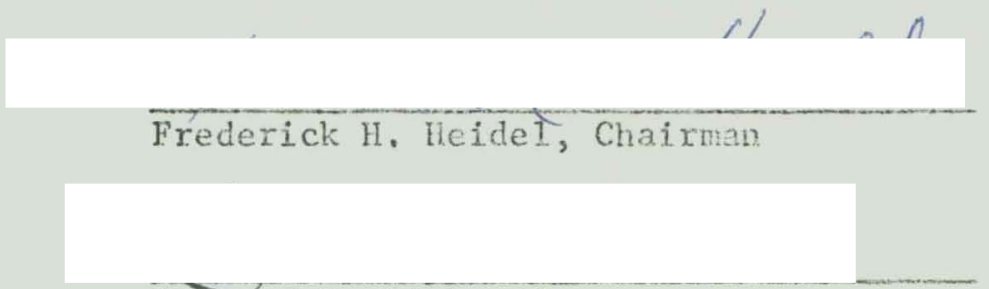

Leonard B. Kimbrell

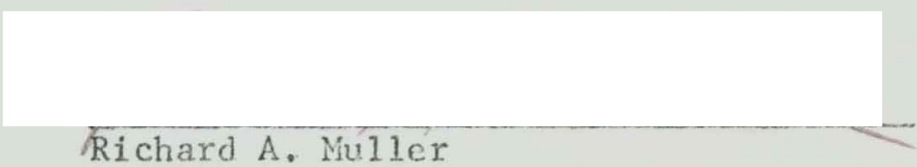

Richard A. Nuller

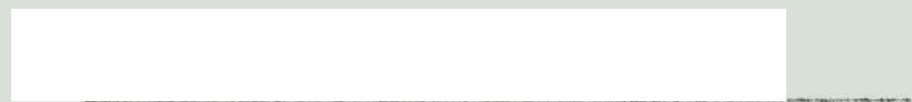

Richard J. Prásch

APPROVED :

Frederick $\mathrm{H}_{3}$ Heidel, Head, Department of Art

David T. Clark, Dean of Graduate Studies

May 17, 1971 
LIST OF FIGURES , , . . . . . . . . . . . . , . . . , iv CHAPTER

I INTRODUCTION . . . . . . . . . . . . . . . 1

II PROBLEMS AND ANALYSES . . . . . . . , . , . 5

Painting One................ 5

Painting Two ............... . . 9

Painting Three, . . . . . . . . . . 13

Painting Four ............. 16

Painting Five ............. 21

Painting Six.............. 24

III CONCLUSION , . , . . , . . . . . . . . 29

BIBLIOGRAPHY OF CITED WORKS . . . . . . . . . . . . , 33 


\section{LIST OF FIGURES}

FIGURE

PAGE

1 Painting one, $28 " \times 41^{\prime \prime}, \ldots . . . . . . . . . . .6$

2 Detail, Painting one . . . . . . . . . . . . 7

3 Detail, Painting one . . . . . . . . . . . 7

4 Detail, Painting one . . . . . . . . . . . 8

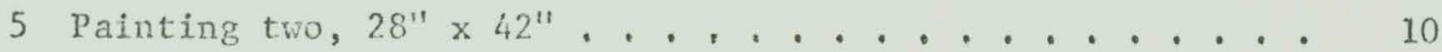

6 Detail, Painting two . . . . . . . . . . . . 11

7 Detail, Painting two . . . . . . . . . . . 12

8 Painting three, $28^{\prime \prime} \times 42^{\prime \prime}$. . . . . . . . . . . . 14

9 Painting four, $28^{\prime \prime} \times 42^{\prime \prime}$. . . . . . . . . . . 17

10 Detail, Painting four . . . . . . . . . . . . . 19

11 Detail, Painting four . . . . . . . . . . . . 20

12 Painting five, $28^{\prime \prime} \times 42^{\prime \prime}$. . . . . . . . . . . 22

13 Detail, Painting five . . . . . . . . . . . 23

14 Painting six, $34^{\prime \prime} \times 593 / 4^{\prime \prime}, \ldots . . . . . . . .25$

15 Detail, Painting six . . . . . . . . . . . 26

16 Detail, Painting six . . . . . . . . . . . . 27

17 Detail, Painting six . . . . . . . . . . . . 27 


\section{CHAPTER I}

\section{INTRODUCTIION}

It seems appropriate, before delving into a study of this nature, to define the terms and set the stage for the work. Volume experience is not a common term. But an experience of volume, while not a conscious one, is common to all: a roon, a box, an open-air theatre, an automoblie interior. All of these represent common volume experiences.

When one tries to define this kind of experience on a two-dimensional surface, the problen becomes not only complicated but necessitates a much keener sense of awareness than the untrained might possess. Therefore, an explanation of the intent of this thesis seems appropriate and necessary,

Volume experience, in the painting problems in this study, is investigated through the means of color variations, as the thesis states. Working with basic color characteristics--hue, value, intensity--becomes the primary concern. The color phenomenon of simultaneous contrast makes the use of color in painting a definite challenge, particularly in a study of volume, Josef Albers states that, "In order to use color effectively it is necessary to recognize that color deceives continually." I It deceives, he believes, because of the role of simultaneous contrast. ${ }^{2}$

\footnotetext{
${ }^{1}$ Josef Albers, Interaction of Color (New Haven and London, 1963), p. 10 ,

${ }^{2}$ Albexs, p. 44 .
} 
Other considerations important to the overall intent of presenting volume experience are first the role of line itself, and secondly, the edge created when two color planes are brought together.

What is meant, then, by volume experience in this thesis work? Briefly, when two colors are put side by side they form an integration of visual stimuli but, also, a definite line. This line is then interpreted to perform as a division of articulation from which the colors might recede or advance, change direction, or be close enough in hue and value to remain as a solid plane of color. Therefore, as colors are used in the various paintings, each time two colors are united, in whatever pattern, they could conceivably present a volume experience. In some instances, when there is a drastic value, hue, or intensity change, volume experience is possibly heightened.

In painting problem number one, the drawn pattern, of course, presents unlimited geometric combinations that could be experienced as volume. The modern painter victor Vasarely has worked with drawings of: similar patterning.

Vasarely attains visual illusions of light, space and movement in his art through clear-cut forms and color harmonies. Geometxic shapes--squares, triangles, diamonds, rectangles, circles, and ellipses--are tilted, repeated, and varied. Painted in flat, vibrant colors and placed against strong contrasting backgrounds, they set up retinal vibrations that dazzle the eye's perception. His work organizes these shapes in complex but precise relations with value and placement controlling the images and the movement. 3

In order to allow the hues themselves to give an experience of volume, or a feeling of spatial tension, the basic pattern of the five

3Va1 Yochem, "Vega I, Victor Vasarely," Instructor, LXXX (December 1970), 60 . 
other paintings is limited to a rectangular motif, This rectangle takes other forms as it is utilized in the works, but it remains basically the same. This strict rectangular pattern was felt necessary so that the hues could function as the volume tools themselves, independent of drawing.

It is felt by this writer that perhaps Piet Mondrian's conclusion that the rectangle is the purest form to use in painting, because of its universal nature, is valid reason for its use in problems investigated in this thesis project. ${ }^{4}$ Another consjderation given to the selection of this form is the unique way in which a subdivision of the rectangle lends itself so naturally to design work. Finally, rectangles placed side by side, in the pattern selected for these painting problems, seemed to be neutral enough that a drawn volume figure vas not apparent, thereby eliminating any consideration of inear perspective.

Color, then, becomes the key to experiencing the pattern, rhythm, depth and kinetic tension of the rectangular planes. John Canaday relates that, "Matisse was learning that color as pure color could have its own rhythms, its own structure, that color could be exalted for itself rather than used as a descriptive or decorative accessory to other elements of a picture." 5 Color, alone, presents the volume experiences in these works.

The philosophical basis for paintings of this type can be related to Vasarely's view of the artistic expression of contemporary societies. Vasarely states:

${ }^{4}$ John Canaday, Mainstreams of Modern Art (New York, 1966), p. 491. ${ }^{5}$ Canaday, p. 403 
My reflections have led me to venture an hypothesis: the proportional enlargement of the motif has become imperious by virtue of the increase in speed in all sectors of our existence. This speed makes us hurried, impatient. We no longer indulge in long contemplation, we have lost the love of detail. On the other hand, techniques have made us lose our manual skill and at the same time have endowed us with apparatus (in this case photography) which instantly give us the details. Our existence has become complicated, encumbered by innumerable utensils, the civilized man's accessories. We lose an enormous amount of time, instead of saving any. Our perception therefore tries to be more quick, we seek the direct and powerful impact of the moment. Large forms, flat and violent colors, responding to this new exigency of man. 6

6 Victor Vasare1y, plastic Axts of the 20th Century, trans. Haakon Chevalier (Switzerland, 1965), p. 33. 
CHAPTER II

PROBLEMS AND ANALYSES

I. PAINTING ONE

\section{The Problem}

By the use of a basic geometric pattern and the variation of essentially two color values, set up a canvas in which colors of one value dominate the perimeter while the central portion of the canvas is dominated by lighter-valued colors. By the use of cool colors, with red as contrast, make volumetric shapes which retain the basic geornetry of the painting but further the illusion of volume.

\section{The Analysis}

An informal but continuously moving color scheme was used in this painting as a basis for the solution. Using blues and greens, with reds as contrasts, spatial relationships and unusual sequences of color were evolved.

The volume changes which are most obvious are the two major divisions, the outside sections and the central sections. Strong, dark values on the top and bottom of the canvas tend to enclose the central spaces more compactly.

The geometry of the work was based on triangles and diamond shapes and used as a design motif. Geometric changes occur in viewing, such as rectangles changing to triangles or parallelograms or diamonds; square 


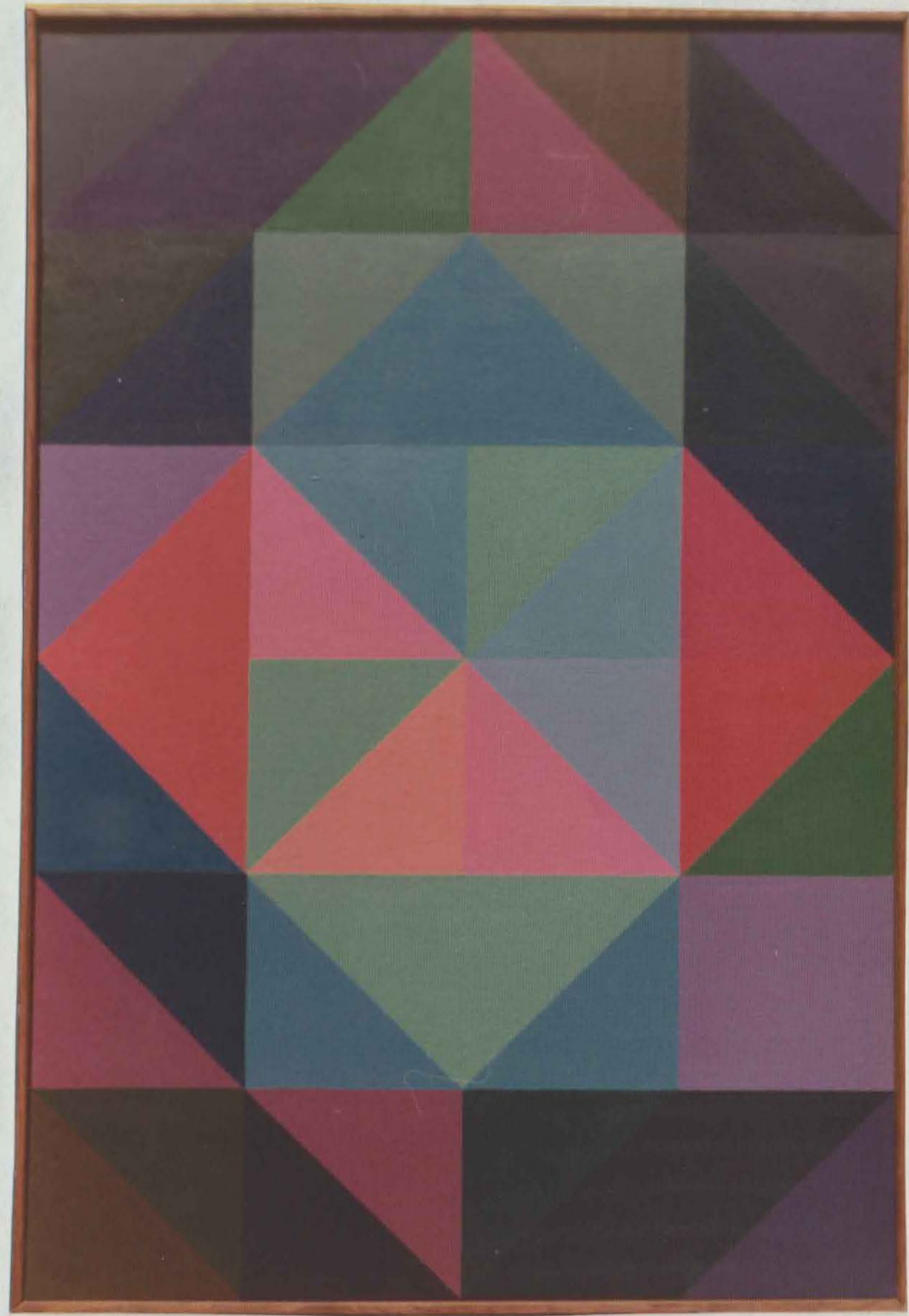

Figure 1. Painting one, $28^{\prime \prime} \times 41^{\prime \prime}$ 
box shapes appearing cubical; and, finally, cubes of red and green interspersed with cubes of red and blue.

These central sections are capable of turning and redirection while parts advance and recede according to color and 1 ight source. For example, there are four central diamond shapes of which the left and bottom diamonds form a diagonal rectangle of reds and greens (Figure 2.). The

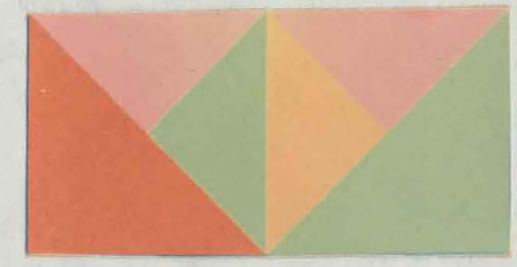

Figure 2. Detail, Painting one.

1ight-valued green activates the bordering reds and provides an edge, where the two join, for simultaneous contrast to aid in moving these green planes outward from the picture plane itself. The reds differ in value but retain enough hue similarities to make the eye first see the basic diamond shapes, then the rectangle, then a subdivision of each shape into smaller triangles. A recycling then occurs. Neither do the reds dominate, nor do the greens. The value changes are instrumental in the experience of volume. A similar analysis could be made with the right and top diamond shapes of this central section, substituting blues

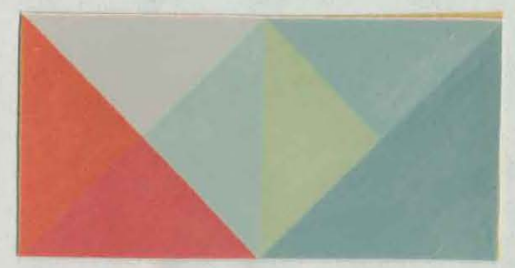

Figure 3. Detail, Painting one. 
for reds and allowing value to play a more active role in the visual experiencing of the tension brought about by these colors (Figure 3 ).

In another instance, value is the factor most important to the volume experience intended. In the lower right section of the painting a warm, dark grey is bordered by purples, a green and a blue (Figure 4).

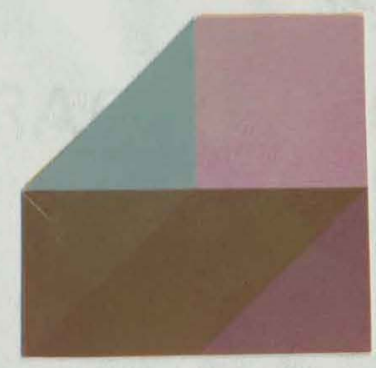

Figure 4. Detail, Painting one

A definite rectangular box formation is created. The grey forms the base, the light-valued purple the far end, and the green-blue combination forms a vertical side. Not only does the green become part of the side, but its slight value change from the grey makes it sometimes act as a continuation of the base plane. In contrast, because the drawn perspective is so obvious, this rectangular box moves forward and backward, the light purple plane forming first the far end, then the near. Sometimes, as different planes meet around the border of the painting, no illusion occurs, merely a combination of like-valued hues and/or a complementary set of hues forming a pattern of color around the central section. Analogous hues are used as a minor addition to the variations outlined. 


\section{PAINTING TWO}

The Problem

This problem will be to create a series of rectangular planes of similar size and shape, eight horizontally and six vertically, which will be basically warm colors stripsd with a cool series of blues and violets, to give an illusion of depth horizontally across the canvas and to create, thereby, an experience of volume.

The Analysis

The basic color system for this problem, as stated above, was warm hues contrasted by blues and violets. As the canvas was being painted, photographs were taken at intervals in order to determine what kinds of value contrasts were being made. Because of the color sensitivity of black and white polaroid film, true readings of value were not obtained. What the photographs did show is that blue-sensitive film tends to group reds and blues together in value, isolating the blue complementaries, the oranges and darker yellows.

As the painting progressed, color relationships were made which secmed to produce strong volumetric illusions. Reds beside blue-violets made definite angles; yellow-greens and oranges of close value produced gent1y fluctuating depth, Strong hue contrasts, such as yellow and violet, made pleasing color relationships but were the most drastic value changes and therefore seemed to produce the most visual volume experience because value changes make planes of color seem to be on different levels, forward and backward, from the picture plane, 


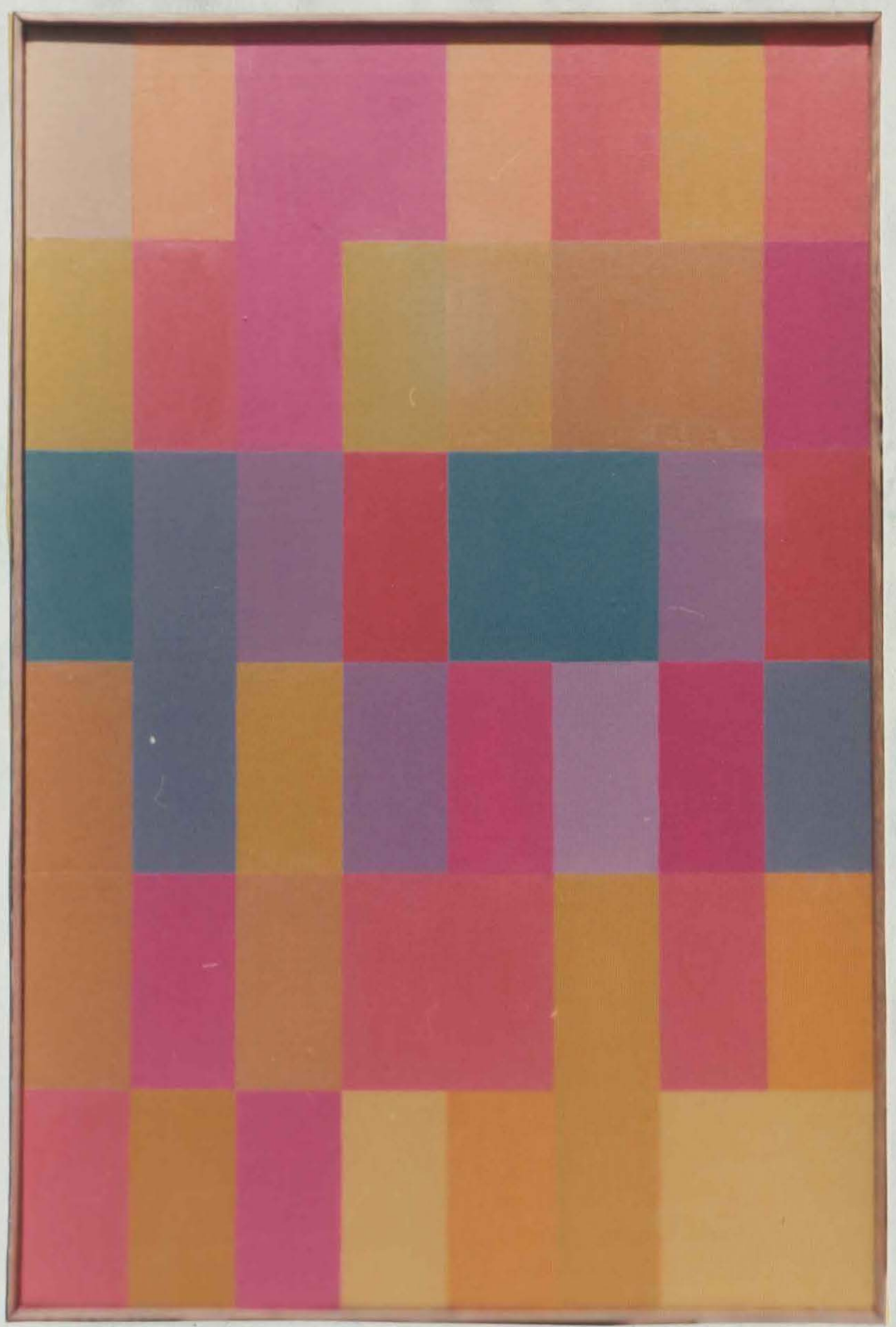

Figure 5, Painting two, $28^{\prime \prime} \times 42^{\prime \prime}$ 
When the canvas is observed as a single unit, the value contrasts seem to lessen and the hue variations mingle to form a definite volumetric pattern. No longer is it easy to detect the single spaces as being similar in size and shape, but only to visually record the hue changes as they occur throughout the pattern.

The proportion of the various hues effect volume experience because one hue is used occasionally in two units, vertically or horizontally. For example, in the right middle section of the painting, a blue extends over two regular rectangular planes (Figure 6). This blue is bordered on

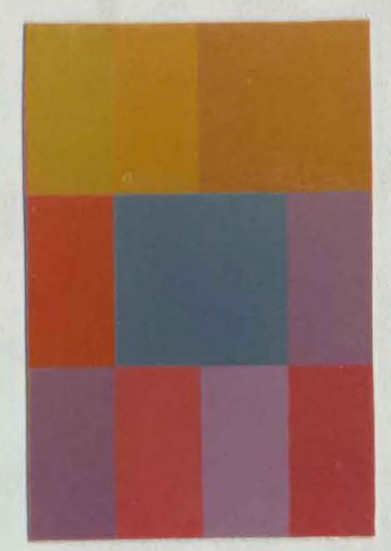

\section{Figure 6. Detail, Painting two}

the right with a red-violet, on the bottom with reds and violets, on the left with an intense red-orange and finally on the top with a variation of yellow-oranges. The blue groups with the red-violets to continue a flat plane. This same blue is pulled by the reds and oranges so that a tension occurs, making the blue seem to turn outward toward the warm reds and oranges but remain stationary at the meeting point with analogous hues. 
In the top left section, a red is used as an extension both vertically and horizontally (Figure 7). On the top line it is bordered by

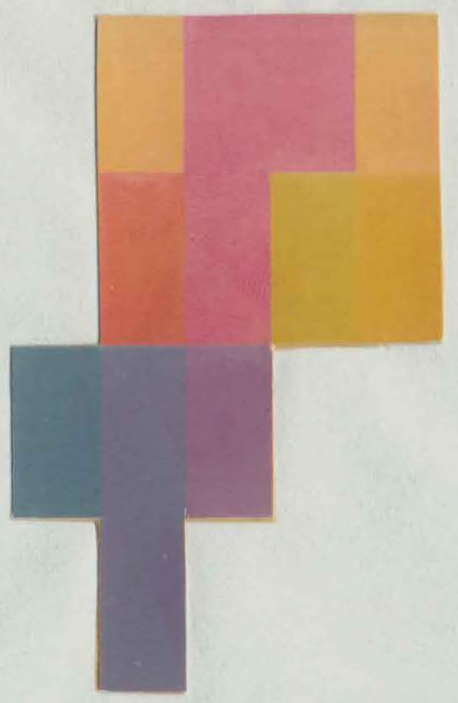

Figure 7. Detail, Painting two

like-planes of lighter-valued orange; on the left bottom a red of similar value meets the plane, but on the right bottom a lighter-valued complementary green is placed. Because this red plane is bordered by changes in value and hue, it seems to stay in the background on the top and then move outward toward the bottom. Similar values perpetuate, and stabilize momentarily, the illusion of a flat plane, then the green on the right breaks the illusion because it moves in a new backward direction, leaving the red forward once again. On the very bottom, the red moves into a violet plane of darker value, a portion of another flat plane, this time a group of blues and violets.

Similar instances of grouped planes, vertically and horizontally, occur throughout the painting, each bordered differently, but each reacting in similar ways when met by hue and value changes. 
The color phenomenon of simultaneous contrast is heightened when reds and biues are used side by side, but it lessens when hues of similar origin are used together such as orange and red. This tends to make redirection of color planes more obvious.

A partial illusion of depth is created as the cool-oriented band of color extends across the middle of the canvas. The cool hues do recede at times, but when comparable intensity is maintained with the reds, this just does not occur. Hue contrasts seem to give a more accurate feeling of depth and recession than do intensity and value changes. The painting maintains its intended overall varm orientation but, perhaps, fails to produce the intended volume experience.

\section{PAINTING THREE}

\section{The Problem}

In order to make a contrast and comparison with the previous problem, this painting will be patterned similarly, but will utilize extreme value changes. The three top and two bottom rows of horizontal planes will be very low in value, whereas the third row from the bottom will be very high keyed. This value change will then be comparable to the hue changes in the previous problem.

\section{The Analys is}

In contrast to the previous problem, this painting deals with hue changes very subtly and with value changes very drastically. The fnitial volume experience is, of course, observation of the light-valued band of hues as placed against the darker hues. This band of hues cuts across the dark hues in a manner that suggests open space, even open enough to be observed as a separation of the canvas itself. 


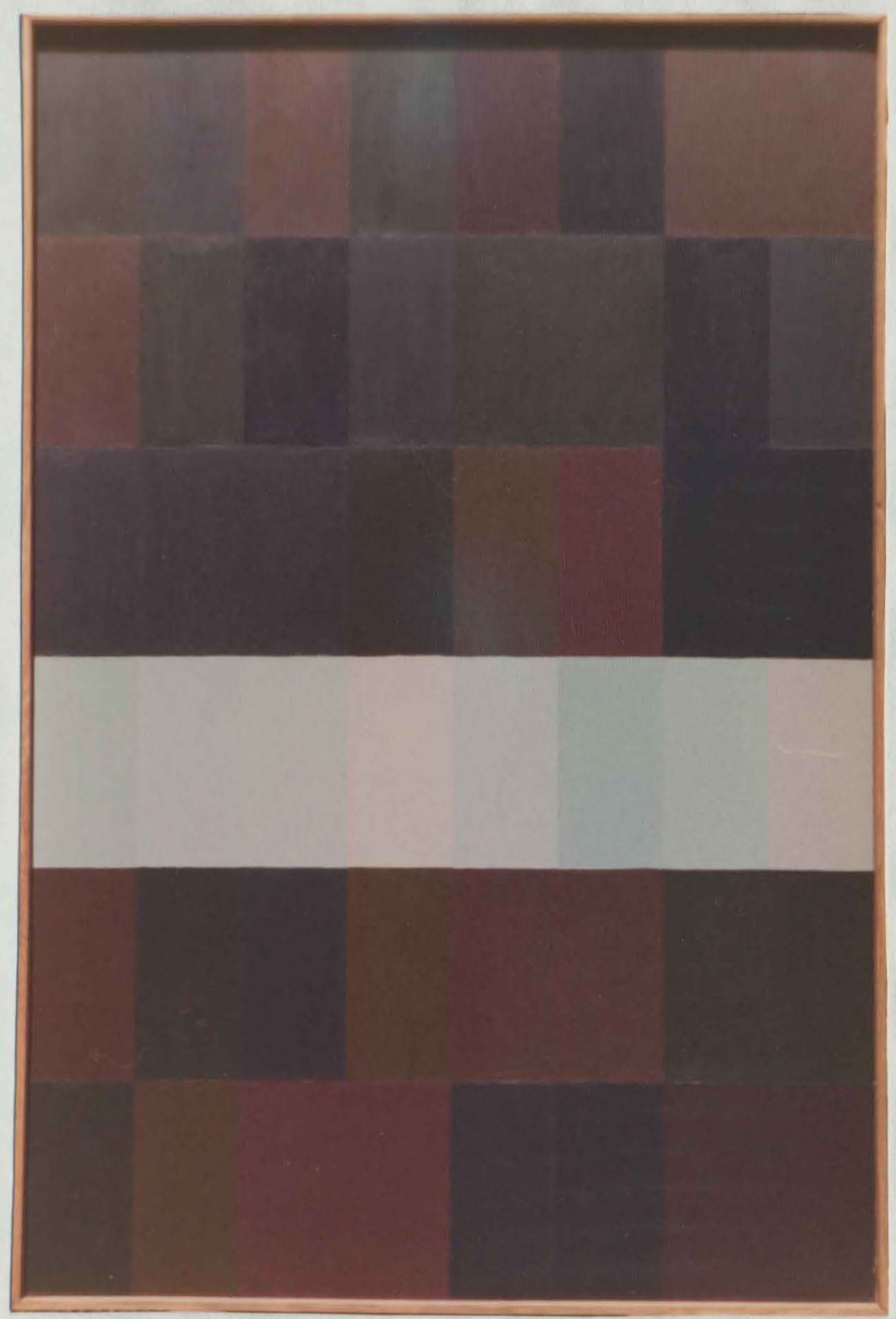

Figure 8. Painting three, $28^{\prime \prime} \times 42^{\prime \prime}$ 
In this painting the hues vary a great deal, but the light-valued colors are ones seen elsewhere in the work in darker values thereby retaining the limited palette and of necessity minimizing hue contrasts. Proportion of hue has a direct bearing on volume experience. In the dark-valued sections of the painting some rectangular planes are continuously painted the same color either horizontally or vertically. Many of the hues which form these dark sections were used because they retain a good deal of their own color qualities when lowered in value with black, and when lowered in intensity with their complement. A red still remains a red, only more rich and vibrant as a darker value than would a yellow, for instance. Oxide greens were used because they seemed to help blues and oranges maintain their distinctiveness at low levels of value.

This particular color pattern was devised to simulate the kinds of color relationships found in painting number two. Red, greens, and oranges exist side by side in order to create edges from which redirection of color planes could occur. Within the dark-valued sections subtle value changes were made so that hue variations could be more easily observed and aid in the visual experience of a fluctuating, non-static area, Although, planes where one continuous hue is used seem to give a stability not otherwise obtained from hue variations. This is not to say that stability is necessary for volume experience, for it is observably not true as a rule, but it serves as a catalyst in the midst of these particular spatial relationships.

When compared to the previous problem, both dea1. with bands of horizontal hues across a field of opposing hues. In problem two the field was intense hue variations whereas problem three is based on value 
variations, Each problem has created an experience related to volume because a similar feeling of spaciousness is evoked by observation. But, hue changes in problem two definitely leave the band of cool hues as part of the composition, and in problem three the value changes in the horizontal band tend to separate and not unite the composition, almost like a sun ray in a darkened room illuminates the area but divides the background into definite spaces.

In direct evaluative comparison to problem two, this painting seems to be more able to evoke a volume experience. It creates a pressure on the lighter-valued band not created in problem two on the cool band. This pressure causes a separation of the extreme values. But, another pressure exists for grouping of similar colors in whatever value they are painted. This occurs as light-valued colors are used which are derived from the same base as the darker ones. Therefore, a division occurs in a united background, a division of degree but not of kind.

\section{IV, PAINTING FOUR}

The Problem

Within a series of planes on the canvas, predetermined in a random geometric balance, apply hues in a manner so that there is evidence of advancing and receding colors, a "working" of colors side by side in a very close value relationship, and a creation of an illusion of spaciousness and volume, Red, in a dark- and light-valued dual role, will be utilized as an accent color.

The Analysis

In this problem colors are used in a very definite sequence for 


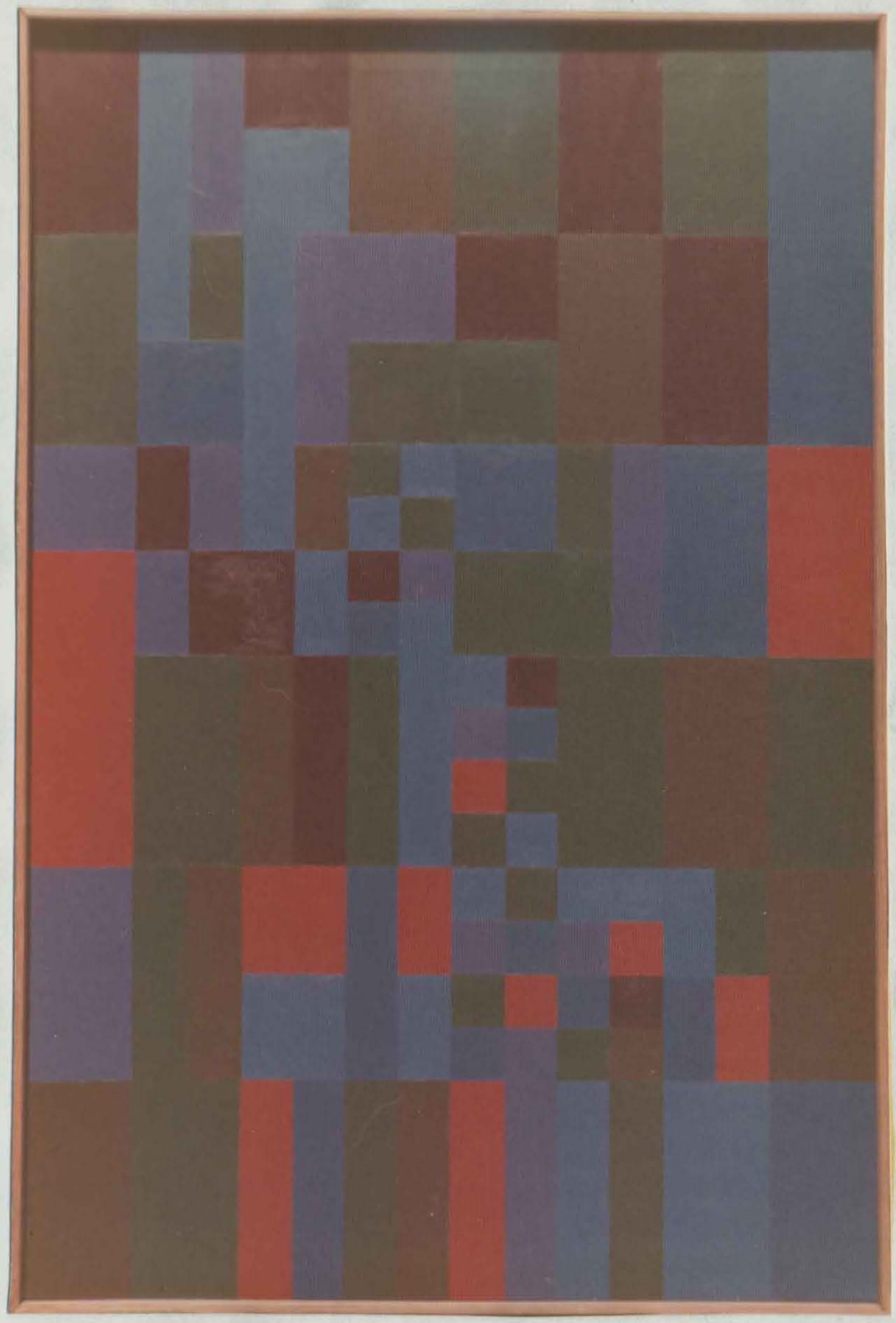

Figure 9, Painting four, 28" $\times 42^{\prime \prime}$ 
very definite purposes. Each hue variation is therefore discussed as to its intent and ultimate function,

BIue. Planes for this color were selected to form a semi-continuous diagonal across the canvas from left top to right bottom.

Green. These green planes were set up to counter-balance not only the blue of the previous planes, but also the strong diagonal made by these blues. These planes were not necessarily diagonal in nature, but are used as an horizontal axis below the middle and a vertical axis from top to bottom somewhat centered.

Orange. The orange planes are used in an inverted " $v$ " shape from top middle to each lower side. The low value of the orange was selected to stay within the general value scale set up with the original blues. Also, the orange-blue complement was intentionally used as hue contrast. Blue-violet. In order to retain the feeling of the coolness of the whole painting, the blues in particular, this blue-violet was used in the upper left very extensively and then periodically throughout in smaller quantities. It serves as a bridge from the blues to the reds.

Chromium Green, This green is used primarily as a smaller inverted " $v$ " shape within the boundaries of the larger orange of the same pattern. Because this color retains much of its original intensity, it was a good optical balance to the following red.

Dark Red, Red in this shade seems to have a cooling effect upon the colors around it. Prinarily, it is used in the upper left section and intentionally isolated from the warner red to be introduced later in the lower half of the painting.

Phthalocyanine Blue, At this point the introduction of an additional blue seemed repetitive, but as it was applied throughout the work, 
it pulled together the blues, greens, and violets. A more unified pattern seemed to result.

Warm Red. These warm red planes in the lower half of the painting were, at first, shocking. After more planes were painted, it became a key hue variation, in addition to counter-balancing the deep red on the top. The value of this hue was in keeping with some of the previous greens and blues which tend to perpetuate the activity of the painting.

By keeping value contrasts to a minimum and using hue variations within a cool range, a volumetric feeling was produced. Color planes, broken fxom the previous eight horizontal and six vertical rectangles into smaller units, were given emphasis in pattern and drawing which ultimately helped create a feeling of volume. But what seemed to be the most important element necessary for this feeling was the proportion and proximity of hues. Planes advanced and receded; they turned very sharply around corners when painted with complementary hues; and collectively, the planes created a network of pulsating hues which, in turn, seemed to present a volume experience.

As stated earlier, red was used in a dual role of dark and warm. These red planes were intended as accents to the cool hues used throughout the painting. The reds are used as an instrument for the advancement and recession of colors around them. For example, a light red square plane is surrounded by blues, greens and violets of the same size and shape; this gives opportunity for cubic observation to occur (Figure 10).

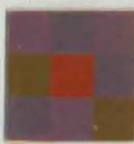

Figure 10, Detai1, Painting four 
The 1ight red becomes the top of a cubic box, the other colors act as sides and top and bottom. In another instance, the light red easily reads as a side panel to a darker box front. Other similar patterns are formed throughout the work, in most instances where these accent reds are used,

The drawn pattern of this painting, also, provides opportunity for movement and volume experience. When the large rectangular planes are divided into smaller areas, four and eight each, eye movement is greater than when the undivided sections exist beside one another. There is a more active fluctuation of color and therefore a greater possibility of cubic formations catching the eye,

In addition to more activity, the small divisions are often attached by color to larger ones which aid in making the surface appear as a woven pattern. They move into other parts of the painting, never still long enough to appear static in any way, but dynamic in nature.

Along the bottom row appears a series of elongated rectangles that draw attention to that area (Figure 11). They move into the central

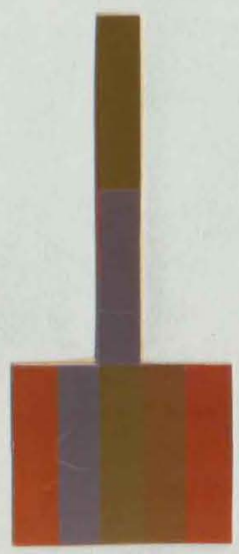

Figure 11. Detail, Painting four 
portion of the painting because of their definite upward thrust, A1so, they give an illusion of a convex plane bordered on each side by a warm red and centered by a green rectangle leading upward into a similarlyshaped blue rectangle, which in turn is topped by another similar green shape. These alternating rectangles create a convex plane in a vertical manner, in direct opposition to the convex horizontal plane along the bottom,

The outline for this problem calls for a "working" of colors, side by side. In order to have a working of colors, there must be some kind of visual relationship. In this painting the relationships are created by likenesses in value (green and orange), by complements used together (orange and blue; reds and greens); and by the usage of analogous colors (blues and violets; violets and reds). A working of colors gives a vis-ual message. Hopefully it nakes sense to the rational, satisfies an esthetic quest, and gives the observer a feeling of balance and color harmony.

\section{PAINTING FJVE}

The Problem

By using the same basic dxawn pattern of eight horizontal and six vertical rectangular planes, originating in problem two, create within these a feeling of spatial tension through the utilization of highvalued hues, Vary the warms and cools in order to develop an alternating concave, convex pattern horizontally across rows of planes, and a vertical accordion pattern. 


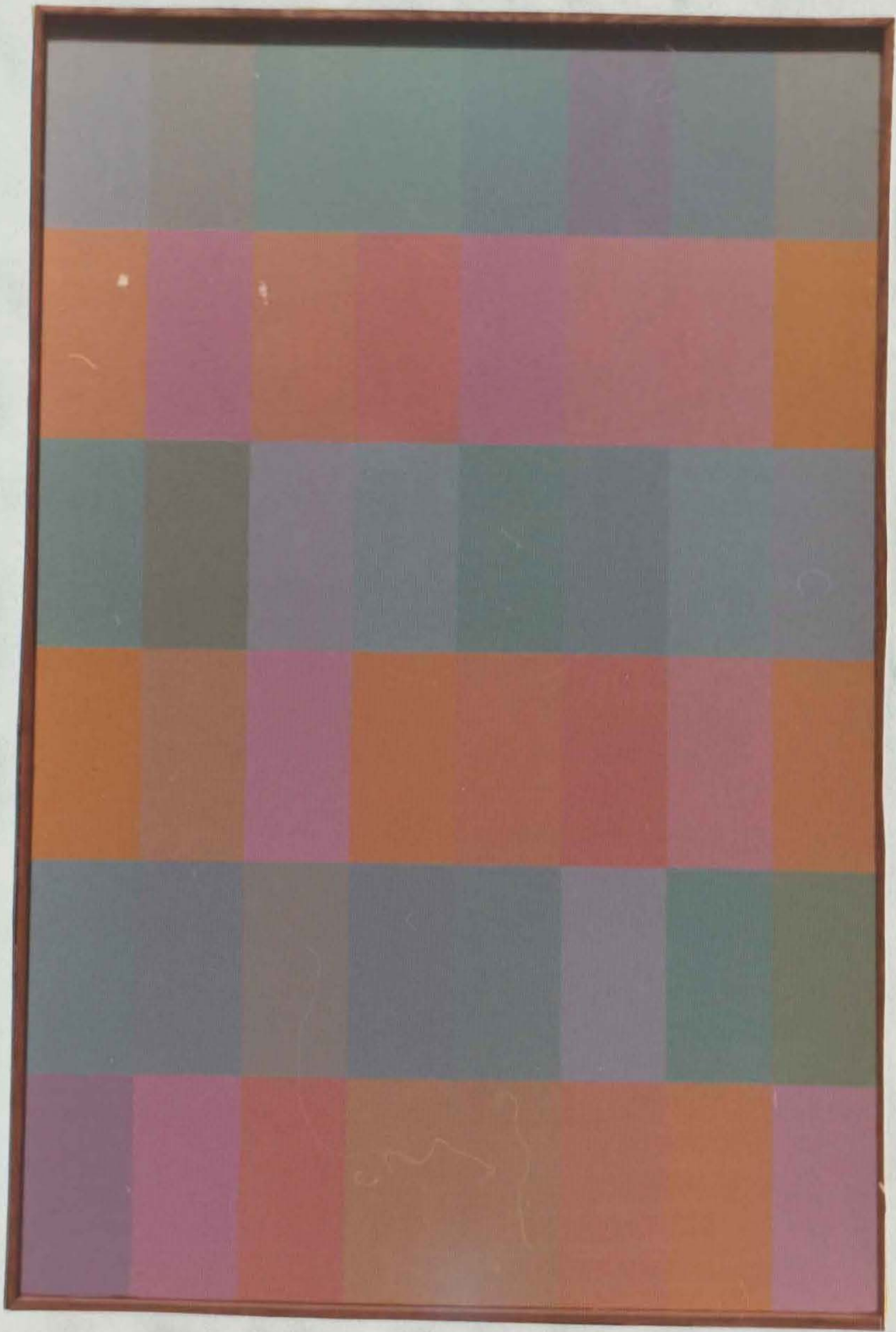

Figure 12. Painting five, $28^{\prime \prime} \times 42^{\prime \prime}$ 
The Analysis

Unlike the previous four problems, this painting makes an emphasis on the horizontal rows of planes in more than a casual way. There is a definite division between each row made obvious by the use of cool and warm colors.

In keeping with the intent of the outlined problem, warms and cools are varied so that a visual pattern of concavities and convexities occur mainly as it is viewed from row to row vertically. Sometimes this concave-convex system works horizontally across each row, particularly, for example, in the bottom row (Figure 13). The cools have a tendency

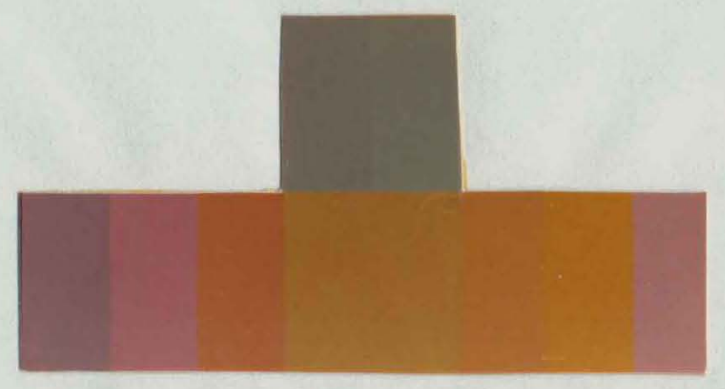

Figure 13. Detail, Painting five

to recele and the warm hues stay forward from the cool stripes because both are generally similar in intensity and value, and because the cool hues are regressive and able to stay in the background when placed next to reds and yellows.

When color relationships occur, such as two spaces of yellow-ochre bordered on the top by two blues, a common central point is set into activity (Figure 13). This point recedes and advances repeatedly so that motion is indicated. Other such instances occur in the painting with minor changes from cool to warm hues. 
The most important event, hovever, is the hard edge produced between each horizontal row from which much action begins, Each individual row plays its own role in the accordion-type folding seen as an overall pattern. Blues and greens, again, provide a background plane upon which is seen a warm combination of colors. A vivid display of color relationships occur, row after row, so that one row bends into the other, but paradoxically, turns abruptly to form an edge. From this edge the activity of the painting is carried out.

\section{PAINTING SIX}

The Problem

This problem will be designed to bring together the various elements that have been featured separately in previous problems. Contrasts in hue, value, and intensity will alj be included. The varied pattern will be based on the rectangular planes outlined in other paintings but will be subdivided into smaller individual units, both horizontally and vertically, By utilizing value changes within this type of drawn pattern, by changing hue intensity, and with the use of many basic colors, both warms and cools, create visual experiences of spatial tension.

The Analysis

By bringing together the major characteristics of color in one composition, as opposed to dealing separately with each, an excitement was produced for this painter. Value and intensity distinctiveness became easier to distinguish and then were used more discerningly.

The design in this painting lends itself to sone observation. The six horizontal bands are observed as such, but flow into each other so 


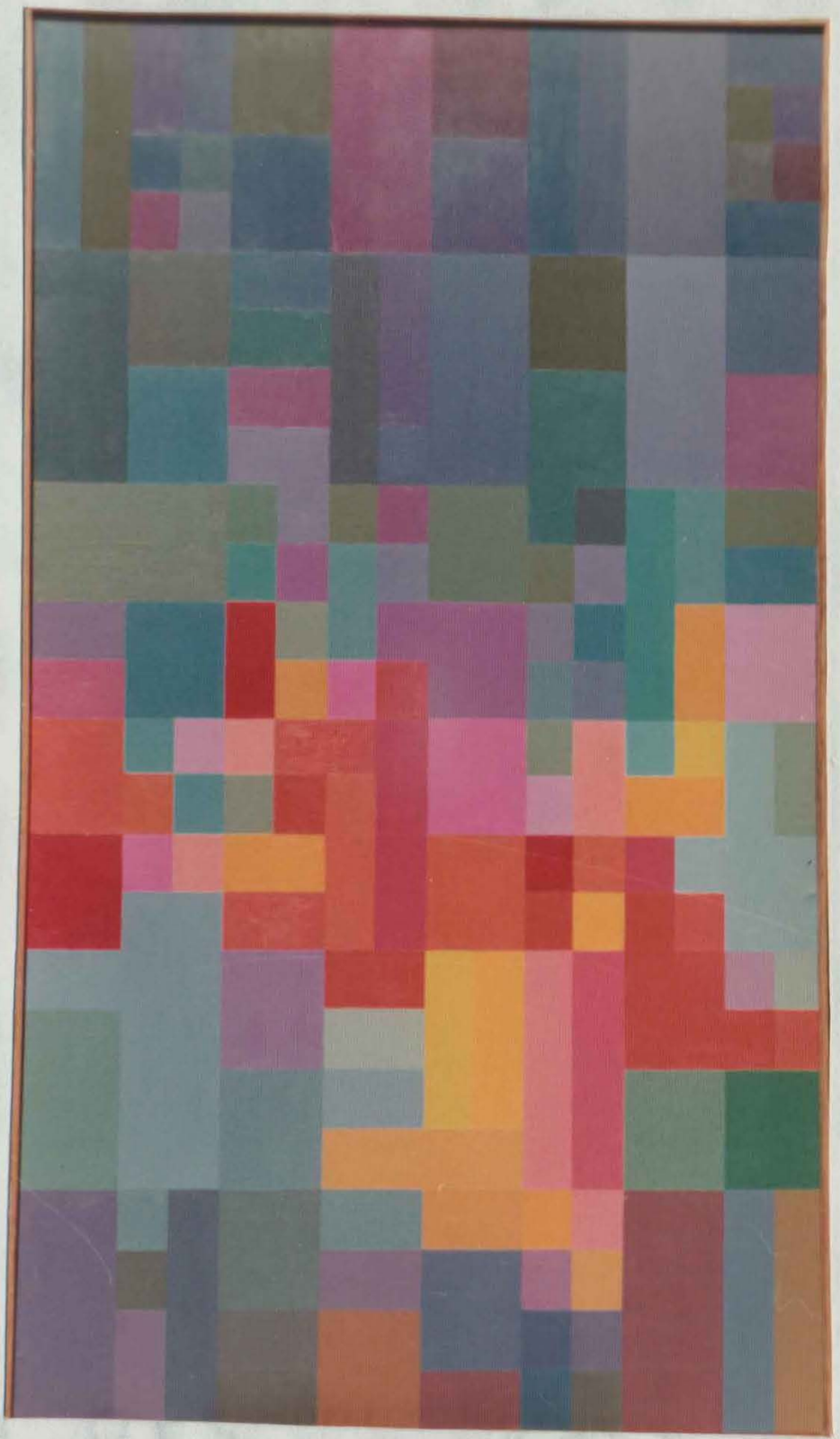

Figure 14, Painting six, 34" x $593 / 4^{\prime \prime}$ 
that a definite continuity exists. There is an inside rectangular shape of lighter-valued colors which tends to bring focus upon the warm midsection (Figure 15). The top half of the painting is predominanty cool

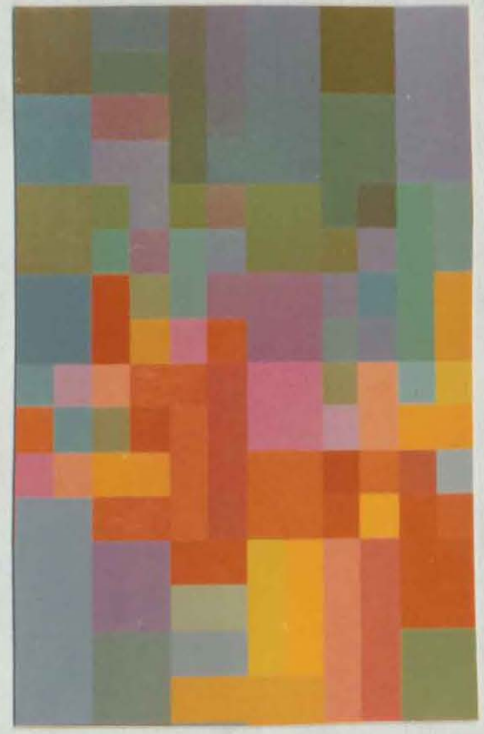

Figure 15, Detail, Painting six

and the bottom half warm, but, again, they are united because of value and intensity likenesses acting as transitions. The intensity of the cool colors toward the bottom is lowered. High-intensity blues surrounding the mid-section give a feeling almost related to spaciousness, airiness, and lightweightedness in feeling and appearance.

As stated repeatedly in this work, especially in the problem ana1yses, intensity seems to hold the colors together, but value gives an edge from which the advancing and receding of colors takes place, sometimes simultaneously,

Simultaneous contrast, on the other hand, exists, especially between like-valued colors, warm or cool, and less movement of colors is observed than when value changes are heightened. A volume experience is 
also less observable. But after-images play a major role in the activity of the whole painting. This phenomenon relates the color usage to a kinetic energy experience, As quoted at the end of Chapter I, some of Vasarely's paintings set up "... retinal vibrations that dazzle the eye's perception." So, too, do the warm colors and their after-images in this work act as instigators to set in motion all hues, side by side. This very activity of colors is the key to the experience of spatial tension. At one point a high-intensity red is bordered on the top with a like-intensity green but on the bottom with a higher-valued orange (Figure 16). The red seems to become an inclined plane, recessive next to green and very forward next to the orange plane.

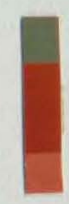

Figure 16. Detail, Painting six

Red, in another instance, changes in four steps to orange. The value changes from the red to the orange, dark to light, so that the lighter-valued hue stays forward and then turns abruptly when bordered by a cool hue (Figure 17). Depth is created by the overa11 11lusion of advancing warm colors and receding dark-valued and low-intensity hues.

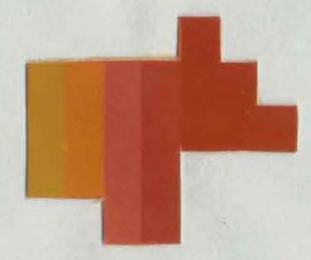

Figure 17, Detail, Painting six 
This painting has an analogy in music. The basic form of a sonata is $\mathrm{a}-\mathrm{b}-\mathrm{a}$, or tonic to dominant to tonic, The sonata changes from key to key as it moves, ending in the same key as its beginning. The color key of this work is low cools at the top, moving into high-valued and warmer color keys, and then beginning to move back into the cool range through lowered intensity. A similar feeling is evoled in both the sonata and the painting. The magic of a sonata in its tendency to move the listener is, then, analogous to the feeling of space and value tension to the observer of this painting.

A second analogy is that of a city at night. The lights of the inner-city illuminate the horizon and the far sides of the buildings within its borders. In drawing this kind of analogy one must envision a city and call upon the imagination to furnish the details. This experience is then related to the intent of the painting at the outset, to bring together color characteristics in order to create a visual experience of volume and space. 


\section{CONCLUSION}

Thus the artistic content of one of Mondrian's compositions still depends on the same qualities that have determined the artistic content of all the great works of the past - from the cave paintings on through to those of Mondrian himself - which is, simply, the artist's sensitivity to the rightness of the lines, the forms defined by those lines, and the colors of those forms, in his composition. 1

When one becomes involved in a project; whether it be a hobby, a non-structured study, or a thesis work, certain concepts and ideas force attention to themselves. These concepts may be a review of knowledge attained at a previous time, or they may be a revelation of new information gained througi experiment and observation. This is simply a positive educational process.

The laborious and delightful processes of working through this thesis and paintings have left theix mark. New Ideas, new experiences, and a review of old knowledge have all been part of the system.

Under the 1 abel of new experiences must be 1 isted the work with the many facets of color, Color relationships constantly provide a new exactness for adjustment. Contrasts in hue and value and intensity, especially when dealing with complementaries and simultaneous contrasts, have been of unlimited value. Being able to see fully-saturated colors side by side form a union of stimuli and, at the same time, prove that

${ }^{1}$ Canaday, p, 491. 
visualiy they form an edge from which two directions are taken, certainly becomes a new and exciting experience.

The various patterns used throughout the series of paintings proved, also, to be stimulating and new in concept and reality, The initial subdivision of a rectangle into component parts was undertaken hesitantly but proved to be a valuable step. While the basic pattern of six by eight equally-sized rectangles was good fox certain of the problems, it was not adequate for a complete analysis of color relationships described as the intent of the paintings.

One outstanding example of pattern usage which was deemed necessary was the flexibility of the planes of color so that the proportion of certain ones, and the placement of them, made the difference between success and failuxe in the usage of these colors. Many times, for example, it was necessary to let a green flow past a like-valued blue in order to contrast and compare it with a red or violet to attain the volume feeling required, This became more difficult in the smaller patterns, but again more challenging.

Because the drawn pattern changed so drastically after the first painting, it may $100 k$ as if it does not belong in the series at all. On the other hand, it is completely related in the usage of color and color intensity aspects. After it was determined that a drawn pattern of this type contained too direct an approach to volume experience by the use of linear perspective, a more neutral pattern was sought. This still left painting number one as the springboard to action and therefore it becomes of vital interest in a search for volume experience.

After the drawn pattem was deternined for the remaining paintings, other areas of concern were unveiled. Hue, itse1f, must be dealt with. 
Value contrasts, value likenesses, and value effect must be explored, And, too, intensity was always there to interject its strong will and purpose,

It is felt that this series of paintings accomplished the intent of the thesis, If there should be one painting which most successfully states in color what the thesis states in words, it would be painting six where each aspect of color is included, heightened, refined, and brought into focus as the tension which occurs when colors are used together in this manner.

At the beginning of this chapter is quoted a statement by John Canaday regarding the rightness of what the artist sees as his task in painting. It is an agreeable statement. Between the lines we might read that theory leads a painter in the right direction, giving him knowledge and experience in working with the elements of painting. This theory makes for better judgment and selection. But, above and beyond theory, the artist must do what is right for him to do at the moment. We see through the eye of the painter. His eye becomes, then, the instrument by which the ultimate in his search is observed by the public. The artist has the right to select, reject, innovate, experiment and present his investigation.

What has all this to do with the presentation of volume experience? First of all, it provides a basis for the study as seen through the sensitivity of one painter, and secondly it provides a basis for further search and discovery on a personal level and on a collective level in a classroom situation,

The ultimate value of this thesis will be twofold, as stated above, personal and public. A definite carryover into public school work is 
inevitable. Theory, practice, and experimentation is imparted daily in classrooms. The lessons learned in this thesis will be transferred to students for years to come.

Not only are the methods and theory important here, but the medium opens new vistas in the classroom. Acrylic paints are a definite boon to a high school classroom art experience. The value of using them in this work will, too, be transferable.

Albers said, "Teaching is a matter not of method but of heart." 2 Perhaps all this is beside the point, but then again perhaps it is not. The heart responds more accurately when bolstered by the knowledge of past successes and errors. At least one heart feels that way. 


\section{BIBLIOGRAPHY OF CITED WORKS}

Albers, Josef. Interaction of Color. New Haven and London, 1963.

Canaday, John, Mainstreams of Modern Art, New York, 1966.

Vasare1y, Victor. P1astic Arts of the 20th Century, ed. Marcel Joray, trans. Haakon Chevalier, Switzerland and Nev York, 1965.

Yochem, Val. "Vega I, Victor Vasarely," Instructor, LXXX (December 1970), 60. 